\title{
Diethylpropion Hydrochloride
}

National Cancer Institute

\section{Source}

National Cancer Institute. Diethylpropion Hydrochloride. NCI Thesaurus. Code C47486.

A sympathomimetic amine structurally similar to amphetamine with anorexiant activity. Diethylpropion hydrochloride stimulates the central nervous system and increases the release of norepinephrine and dopamine from nerve terminals and inhibits their uptake. This suppresses appetite, increases motor activity, causes euphoria, mental alertness and excitement. This drug may also cause an increase in heart rate and blood pressure. Diethylpropion hydrochloride is used in the treatment of obesity. 